\title{
Study on Spatial Scale Transformation Method of MODIS NDVI and NOAA NDVI in Inner Mongolia Grassland
}

\author{
Hongbin Zhang ${ }^{1,2,3}$, Guixia Yang ${ }^{1,2,3}$, Qing Huang ${ }^{2,3}$, Gang Li $^{1,2,3}$, Baorui Chen ${ }^{1,2,3}$,
and Xiaoping Xin ${ }^{1,2,3, *}$ \\ ${ }^{1}$ Hulunber Grassland Ecosystem Observation and Research Station, \\ Beijing, 100081, China \\ ${ }^{2}$ Key Laboratory of Resource Remote Sensing and Digital Agriculture, Ministry of \\ Agriculture, Beijing, 10008, China \\ ${ }^{3}$ Chinese Academy of Agricultural Sciences Institute of Agricultural Resources and Regional \\ Planning, Beijing, 100081, China \\ hbzhang@caas.net.cn
}

\begin{abstract}
Based on MODIS NDVI and NOAA NDVI datum, covering the primary grassland types of Inner Mongolian in growing seasons from 2000 to 2003, this paper analyzes annual variation rule of the relationship between MODIS NDVI and NOAA NDVI datum. We use the theory of statistics to discuss the spatial scaling methods between different resolutions images of remote sensing in large-scale spatial extent. At the same time, we build spatial scaling model by MODIS NDVI and NOAA NDVI datum of July and August in 2002, and apply it to the 2003's NOAA NDVI datum, then take the survey datum in field to validate the precision of the model. The result indicates that this spatial scaling method is effective, and the model could be applied to other times. This method makes it scientific and effective to analyze and compare the result of monitor by NOAA NDVI and MODIS NDVI of different times in grassland.
\end{abstract}

Keywords: Spatial scaling, grassland remote sensing, MODIS, NOAA.

\section{Introduction}

At present, remote sensing technology has already become the mainly acquisition method and important study means for macroscopic ecology subject. Because satellite sensor imaging has instantaneity and periodicity features coupled with weather factors (such as cloud, rain, snow and so on) affecting sensor imaging, any sensor can't supply the enough image datum to covered the whole grassland in any times ( Li Xin et al., 2007). That's say, shortage of time series image in the same region or spatial

Corresponding author. Address: Chinese Academy of Agricultural Science Insititute of Agricultural Resource and Regional Planning, No.12 Zhongguancun South St., Haidian District, Beijing 100081, China. Tel:+86-10-82109622-138, xinxp@sina.com. 
image data in the same time for macroscopical ecology system study. Especially in long time serial and large spatial scale ecology system monitoring study, this problem is the most serious. So how to effectively integrate multiple-source remote sensing datum and different resolution (spatial resolution, temporal resolution) image datum for macroscopical ecology monitoring study has become difficulties in current. Especially in recent years, many experts and scholars at home and abroad have already developed search. Mayaux and Lambin adopted two-steps transformation method to make vegetation area scale transformation based on four spatial exponential relations of TM and AVHRR in 1995(Mayaux P et al., 1995). Wang Kaicun and so on analyzed shortwave albedo of MODIS and AVHRR data and compared the differences between them in details in 2004(Wang kaicun et al., 2004). Kevin Gallo and so on analyzed differences of NOAA NDVI and MODIS NDVI in details and built up NOAA NDVI and MODIS NDVI data relational model of types of farmland, grassland, evergreen broad-leaf forest, shrubbery, city in 2005(Kevin Gallo et al., 2005). Bao Pingyong and so on analyzed surface albedo production of same time's ETM+ and MODIS data and compared differences of surface albedo of forest land, farmland, grassland, water, city, river shoal, exposed soil and exposed rock in 2007(Bao PIngyong et al., 2007). Zhang Wanchang and so on took on scale transformation study based on LAI index inverted from ETM+ data and attempted to bring forward a new more effective scale transformation method based on NDVI unmixed pixels in 2008(Zhang Wanchang et al., 2008). Wang Peijuan adopted ETM+ and MODIS data to investigate spatial scale transformation method of forest coverage net primary productivity in Changbai mountain nature reserve (Wang Peijuan et al., 2007).

This paper took Inner Mongolia grassland as an example to study spatial scale transformation method among large scale grassland different resolutions remote sensing data. Because MODIS and NOAA data have lower spatial resolution features (Huang Jiajie et al., 2003; Potte, C et al., 2003; Steven, M. D et al., 2003 ), and survey region is too large, it's difficult obtain high precision land utilization type map and different types of vegetation pure pixels and so on parameters. So we used the theory of statistics to build spatial scaling model of MODIS NDVI and NOAA NDVI datum, and applied the model to time scale application.

\section{Survey Region Overview}

Inner Mongolia grassland is located in hinterland of Eurasian Continent. It is a vast land and has rich and colorful grass types occupying $22 \%$ of our country grassland whole area. at the same time it spans "Sanbei distraction" in our country. It's important animal breeding production base and a natural green protective screen for north china, it takes the role of protection and improvement our country ecology environment. According to Inner Mongolia autonomous region 1:10000000 grassland type map, whole grassland area is $794239.00 \mathrm{~km} 2$. The survey region makes up of Lowland meadow, up-land meadow, temperate steppe, steppe desert, temperate meadow steppe, desert grassland, desert steppe and so on seven types of grassland and whole area is $781587.10 \mathrm{~km} 2$ accounting for $98.4 \%$ of Inner Mongolia grassland whole area. It is the main body of Inner Mongolia grassland autonomous region. 


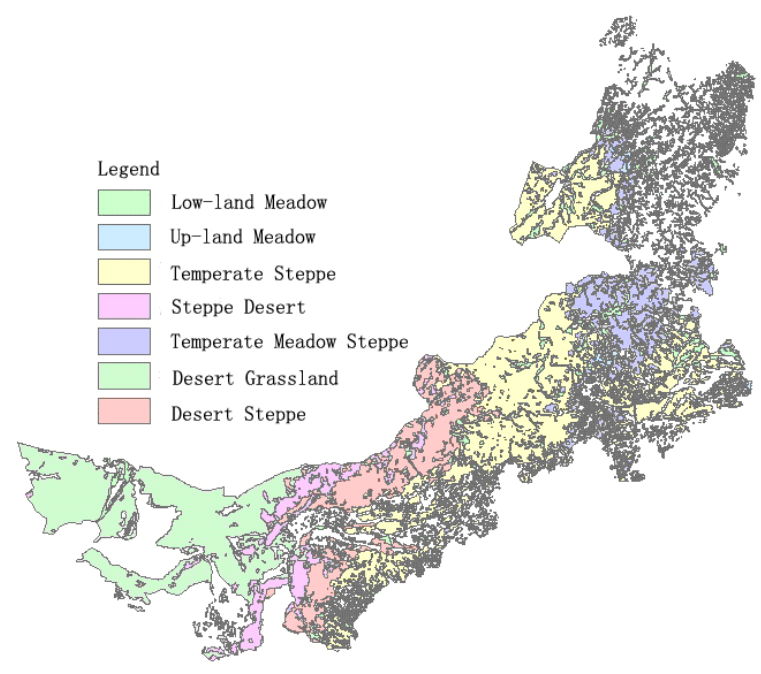

Fig. 1. The Grass type of Inner Mongolia

\section{Study Method}

\subsection{Data Resources}

This paper used the first and second band of MOD09Q1 production provided by NASA. Because MOD09Q1 is 8 days reflectivity production composed by everyday L2G surface reflectivity and affected by weather easily, it is very hard to get the remote sensing data which was not shaded by cloud in a short time (Yan Jianwu et al., 2008; Zhang Lianyi et al., 2008). So this paper applied the maximum value compounding method to obtain monthly NDVI vegetation index data to analyze.

The NOAA data we used is $8 \mathrm{~km}$ resolution NOAA/AVHRR monthly maximum value compounding NDVI production provided by Global Inventory Monitoring and Modeling Studies.

\subsection{MODIS NDVI and NOAA NDVI Data Relation Stability Analysis}

Because this study is involved with spatial scale transformation model applied in time scale, it is necessary to analyze stability of correlation between MODIS NDVI and NOAA NDVI data in long time scale. It is the basic premise to ensure stability and effectiveness of time scale transformation model. This paper selected monthly maximum compounding NOAA and MODIS NDVI data from April to October, in 2000 to 2003, and use ArcGIS 9.0 to calculate correlation of different months NDVI $_{\max }$ between two types of data. Compare fluctuation of correlation in same term and study whether there is stable correlation between them in research area. The results as shown as below: 


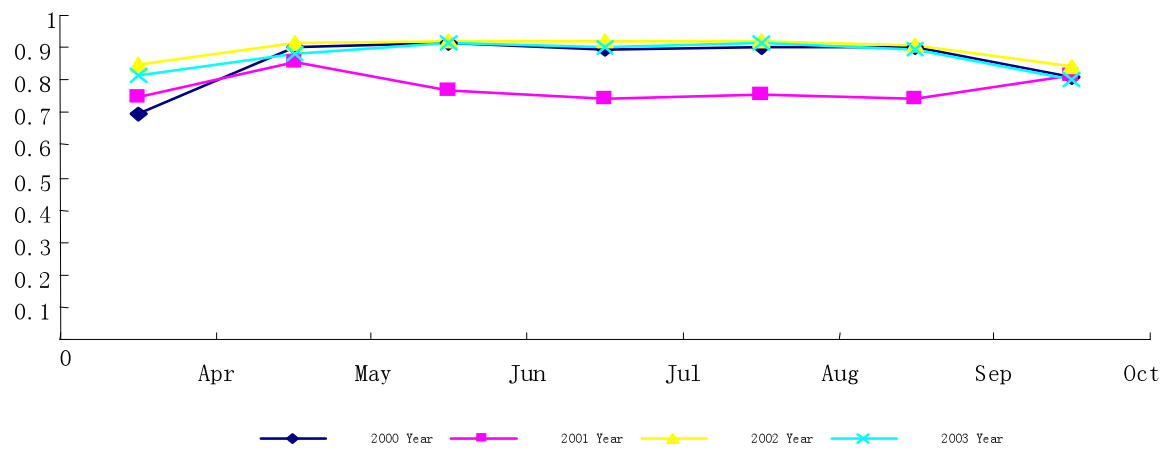

Fig. 2. Analysis of the correlation between NOAA NDVI and MODIS NDVI, 2000-2003

From fig 2, we can see correlation of NOAA NDVI and MODIS NDVI data changed with regularity and the correlation was stable in long time scale between them in growing season from 2000 to 2003 except 2001.

\subsection{Spatial Scale Transformation Method of MODIS NDVI and NOAA NDVI}

Because MODIS sensor is superior to AVHRR sensor in spatial and spectral resolution, MODIS NDVI can reflect grassland vegetation condition more truly. So this paper selected down-scale transformation method that from NOAA NDVI to MODIS NDVI and built scaling model. The detailed method is as below.

Apply systematic sampling to select study samples in MODIS NDVI and NOAA NDVI remote sensing images. Sampling interval is $40 \mathrm{~km}$. Sampling range of MODIS image was an circular region with $4 \mathrm{~km}$ radius, take NDVI mean value as MODIS data sampled value. The Sampling range of NOAA image was a pixel $(8 \mathrm{~km} * 8 \mathrm{~km})$, so we can obtain 533 MODIS and NOAA sample datum every month in research area.

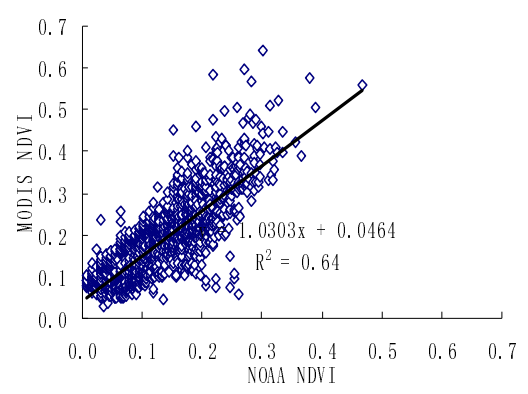

Fig. 3. Comparison of NOAA NDVI and MODIS NDVI in Apr

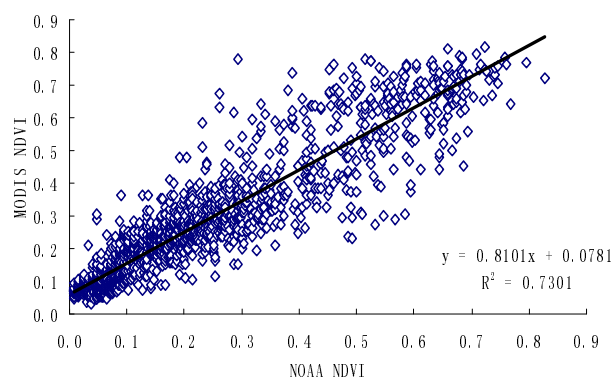

Fig. 4. Comparison of NOAA NDVI and MODIS NDVI in May 


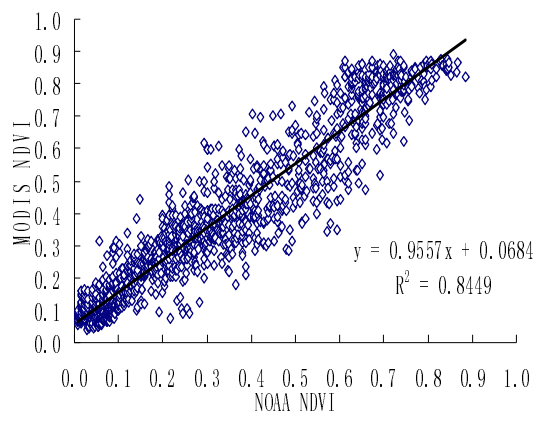

Fig. 5. Comparison of NOAA NDVI and Fig. 6. Comparison of NOAA NDVI and MODIS NDVI in Jun

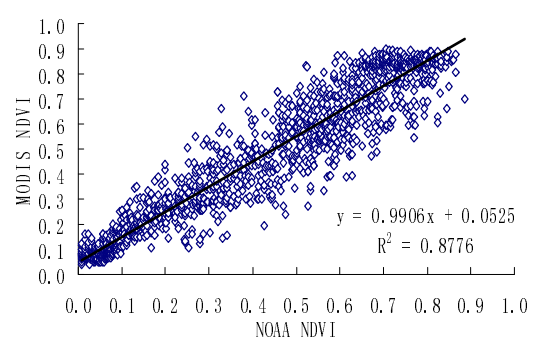

Fig. 7. Comparison of NOAA NDVI and Fig MODIS NDVI in Aug

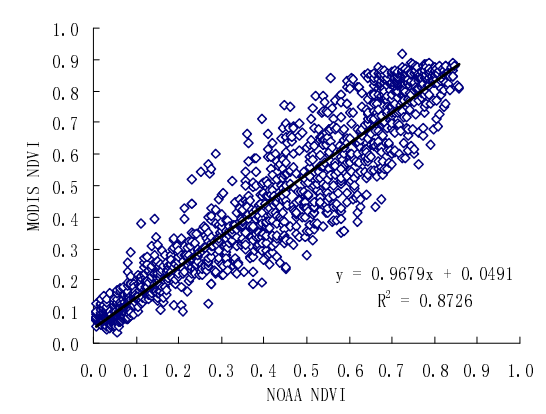

MODIS NDVI in Jul

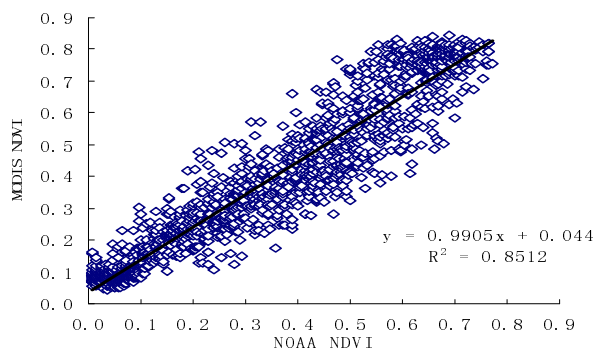

Fig. 8. Comparison of NOAA NDVI and MODIS NDVI in Sep

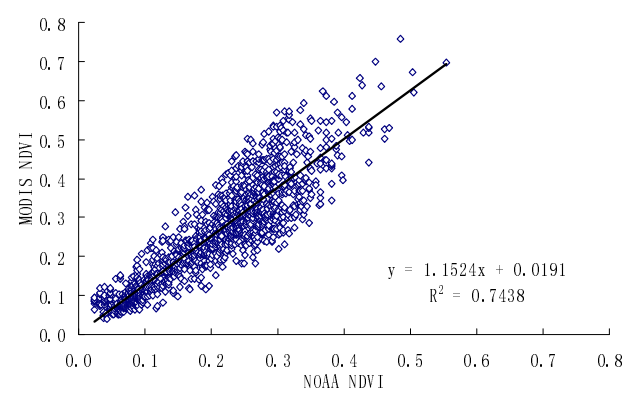

Fig. 9. The Comparison of NOAA NDVI and MODIS NDVI in Oct

From fig 3 to 9, MODIS NDVI and NOAA NDVI data of grassland vegetation in April to October have well linear correlation which increase start at April, reached a peak in August and decrease start at September. As correlation was concerned, April was at lowest, May and October were almost the same, but October was slightly higher than May; June and September were almost the same, but September was 
slightly higher than June; July and Aug were almost the same, but Aug was slightly higher than July; May and October were significantly higher than April; June to September were significantly higher than April, May and October; July and August were significantly higher than June and September.

The change trend of linear correlation between MODIS NDVI and NOAA NDVI data was truly in response to grassland vegetation condition in research area $(\mathrm{Xu} B$ in et al., 2007). The grassland began to growing in April and at this time, the grassland vegetation coverage and biomass were the lowest in growth season. So NDVI index of grassland was very small, when the influence of soil background noise etc on AVHRR and MODIS sensors monitoring relatively the largest, more mistakes resulted. Especially NOAA NDVI data, because of uncertainty of calibration parameter, rang of mid-value and low value excelled 20\%. All of the facts disturbed MODIS NDVI and NOAA NDVI data to obtain the parameters reflecting grassland vegetation condition to a great degree. So NDVI data has too much noise in April and correlation is the worst. In May grassland vegetation coverage and biomass were better than April. The influence of factors of soil background noise etc on AVHRR and MODIS sensors monitoring began to weaken. So correlation of MODIS NDVI and NOAA NDVI rose notably compared with April. In June, grassland vegetation coverage and biomass had a further marked increase and correlation continued to strengthen. July and august were the two months in which grassland vegetation condition were the best in the whole growth season. So correlation of July and August were higher than the other months and grassland vegetation condition in July was better than that in August. But because saturation effect of AVHRR and MODIS sensor bothered to obtain NDVI data reflecting truly grassland vegetation condition, correlation of August was a little higher than that in July. In September, grassland vegetation coverage and biomass began to decrease, but because there was a lot of hay in research area which decreased the influence of soil background noise on AVHRR and MODIS sensor monitoring, association relationship of September was just a little higher than June. In like manner, correlation of October was just a little than May.

\section{Spatial Scale Transformation Method Application and Verification}

The NDVI values of July and August represented the maximum value all the year round in research area. So NDVI value of July and August were applied the most widely in biomass yield estimation. Because of shortage of ground surface survey data except July and August, this paper mainly validated the precision of spatial scale transformation model between MODIS NDVI and NOAA NDVI data of July and August in 2002, according to the spatial scale transformation discussed in 3.3, linear spatial transformation model was built up and extrapolated to NOAA NDVI data of July and August in 2003. Taken use of MODIS NDVI and NOAA NDVI data and survey data to validate and verify spatial scale transformation precision when extrapolated to time scale and practicability. Specific process as follows:

Adopt systematic sampling method, draw 533 samples in $8 \mathrm{~km}$ resolution NOAA NDVI and $250 \mathrm{~mm}$ resolution MODIS NDVI of July and August in 2002. According to linear correlation, built up spatial scale transformation model of NOAA NDVI and 
MODIS NDVI in July and August (table 1). Take advantage of this model and Erdas 9.0 to resample pixels (to $250 \mathrm{~m}$ ) and linear process to obtain transformed $250 \mathrm{~m}$ NOAA NDVI data of July and August in 2003.

Use survey datum of July and August in 2002 and MODIS NDVI data of July and August in 2002 to build up regression model to get the regression formula: $\mathrm{Y}=11.2620+179.6915 \mathrm{X}$ (Y: dry biomass; X: MODIS NDVI). Input above transformed $250 \mathrm{~m}$ resolution NOAA NDVI data to model and generate grassland vegetation biomass distribution map of July and August in 2003 separately.

Use survey datum of July and August in 2002 and untransformed 8km resolution NOAA NDVI data to build up regression model to get the regression formula: $\mathrm{Y}=25.9050+129.6058 \mathrm{X}$ ( $\mathrm{Y}$ : dry biomass ; X:NOAA NDVI vegetation index). Input above uncorrected $8 \mathrm{~km}$ resolution NOAA NDVI data in 2003 to model and get ground biomass distribution map in research area of July and August in 2003.

Table 1. Spatial Scaling Model of MODIS NDVI and NOAA NDVI in 2002

\begin{tabular}{cccc}
\hline & Spatial Scaling model & $\mathrm{R}^{2}$ & $\begin{array}{c}\text { Sum of Squared } \\
\text { Residuals }\end{array}$ \\
\hline July & $\mathrm{Y}=0.028442+0.975085 \mathrm{X}$ & 0.93 & 2.22 \\
August & $\mathrm{Y}=0.027654+0.983479 \mathrm{X}$ & 0.93 & 2.29 \\
\hline
\end{tabular}

Note : Y:MODIS NDVI X:NOAA NDVI

At last, take advantage of survey datum of July and August in 2003 (29 ground surface samplings in July and 52 ground surface samplings in August) to verify biomass distribution map and analyze precision difference. The results as follows:

Table 2. Result of Verify Spatial Scaling Model of NOAA NDVI and Biomass, Jun and Jul 2003

\begin{tabular}{|c|c|c|}
\hline NOAA NDVI & Mean relative bias $\bar{\Delta}$ & $\begin{array}{l}\text { Mean absolute } \\
\quad \text { bias } \bar{V}\end{array}$ \\
\hline Untransformed July data in 2003 & 0.36 & 38.87 \\
\hline Transformed July data in 2003 & 0.35 & 40.44 \\
\hline Untransformed August data in 2003 & 0.28 & 47.34 \\
\hline Transformed August data in 2003 & 0.27 & 42.08 \\
\hline $\begin{array}{l}\text { Untransformed July and August data in } \\
\qquad 2003\end{array}$ & 0.31 & 44.49 \\
\hline $\begin{array}{l}\text { Transformed July and August data in } \\
2003\end{array}$ & 0.29 & 41.75 \\
\hline Note : mean relative bias : $\begin{aligned} \bar{\Delta} & = \\
\overline{\mathrm{v}} & =\sqrt{ }\end{aligned}$ & $\frac{\left.|\mathrm{d}| / \mathrm{x}_{\mathrm{i}}\right) / \mathrm{n} \quad \text {; mea }}{|\mathrm{d}|^{2} / / \mathrm{n}}$ & lute bias : \\
\hline
\end{tabular}

Results of verify in table 2 indicated that NOAA NDVI in 2003 transformed from 2002 by spatial scale transformation model had very high monitoring precision to 
grassland biomass and had improved compared with untransformed data. So the spatial scale transformation model can extrapolated in time scale.

\section{Conclusions and Discussion}

1. On the whole, MODIS NDVI was more than NOAA NDVI in value, and they both had high relativity in growth season. The relativity mainly affected by vegetation growth climate condition. That is because when climate condition was better, high coverage of grassland can reduce noise influence of soil background on AVHRR and MODIS sensors imaging. On the contrary, when grassland vegetation condition was bad, noise influence of soil background on AVHRR and MODIS sensors imaging would be increased, resulted correlation of MODIS NDVI and NOAA NDVI decreased. So in research area, correlation of July and August were the highest and April was the lowest.

2. Linear spatial transformation model built up based on MODIS NDVI and NOAA NDVI was stable in time dimension in some degree. After time scale transformation model was extrapolated application, the transformed NOAA NDVI data kept higher monitoring precision of grassland biomass to indicate the model could be extrapolated in time scale. Because vegetation condition in July and August were the best, association degree between MODIS NDVI and NOAA NDVI data were the highest. So stability of spatial scale transformation model built up based on MODIS NDVI and NOAA NDVI in July and August was the best when extrapolated in time scale.

3. This paper based on statistics method, making use of association relationship of 250m resolution MODIS NDVI and $8 \mathrm{~km}$ resolution NOAA NDVI data, spatial transformation model between MODIS NDVI and NOAA NDVI data was built up. But because this method self did not take $8 \mathrm{~km}$ resolution NOAA NDVI data big pixel inner heterogeneity in to account. So relative precision of $250 \mathrm{~mm}$ resolution small pixel of NOAA NDVI data in $8 \mathrm{~km}$ large pixel region was not prompted and this was the shortcoming of the method. In so large spatial scale survey region, conflicted by so many basic data serious limits (such as high precision land utilization map shortage, big mistake in spatial adjustment of low resolution data, different type vegetation pure pixel shortage) It was difficult to adopt other scale transformation method taken spatial heterogeneity into account. Under the premise of ensuring total scale transformation precision, the method adopted by this paper was a scale transformation feasible scientific method in large space range different resolutions remote sensing data.

\section{Acknowledgements}

This work is supported by Special Fund Project for Basic Science Research Business Fee, Institute of Agricultural Resources and Regional Planning, Chinese Academy of Agricultural Sciences and The National Science \& Technology Program (Grant No. 2006BAC08B0404 、2007BAC03A10) and Project 863 of China: (Grant no.2007AA10Z230) and National Natural Science Foundation of China (Grant No: 30770327) and Commonweal Industry Scientific Research Special Funds Project (GYHY200906029-2). 


\section{References}

1. Li, X., Huang, C., Che, T., et al.: Progress and Foresight of Chinese land Data Assimilation System Study. Nature Science Progress 17(2), 163-173 (2007)

2. Mayaux, P., Lambin, E.F.: Estimation of tropical forest area from coarse spatial resolution data: A two-step correction function for proportional errors due to spatial aggregation. Remote Sensing of Environment 53(1), 1-15 (1995)

3. Wang, K., Liu, J., Zhou, X., et al.: Retrieval of the surface albedo under clear sky over China and its characteristics analysis by using MODIS satellite date. Chinese Journal of Atmosphere Sciences 28(6), 941-949 (2004)

4. Gallo, K., Ji, L., Reed, B., Eidenshink, J., Dwyer, J.: Multi-platform comparisons of MODIS and AVHRR normalized difference vegetation index data. Remote Sensing of Environment (99), 221-231 (2005)

5. Bao, P., Zhang, Y., Gong, L., et al.: Study on consistency of land surface albedo obtained from ETM+ and MODIS. Journal of Hehai University (Natural Sciences) 35(1), 67-71 (2007)

6. Zhang, W., Zhong, S., Hu, S.: Spatial scale transferring study on leaf area index derived from remotely sensed data in the Heihe river basin, China. Acta Ecologica Sinica 28(6), 2495-2503 (2008)

7. Wang, P., Xie, D., Zhang, J., et al.: Spatial scaling of net primary productivity based on process model in Changbai Mountain natural reserve. Acta Ecologica Sinica 28(8), 32153223 (2007)

8. Huang, J., Wan, Y., Liu, L.: The character and application of MODIS. Geospatial Information 1(4), 20-28 (2003)

9. Potte, C., Tan, P.N., Steinbach, M., Klooste, S., Kumar, V., et al.: Major disturbance events in terrestrial ecosystems detected using global satellite data sets. Global Change Biology (9), 1005-1021 (2003)

10. Steven, M.D., Malthus, T.J., Baret, F., Xu, H., Chopping, M.J.: Intercalibration of vegetation indices from different sensor systems. Remote Sensing of Environment (88), 412-422 (2003)

11. Yan, J., Li, C., Yuan, L., Chen, Q.: Application summary of EOS-MODIS data in the monitoring of grassland resources. Pratacultural Science 25(4), 1-9 (2008)

12. Lianyi, Z., Gang, W., Luru, B.: Temporal changes of MODIS-NDVI vegetation index and forage biomass in Xilinguole grassland- taking the change from April to September in 2005 as a sample. Pratacultural Science 25(3), 6-11 (2008)

13. $\mathrm{Xu}, \mathrm{B}$., Tao, W., Yang, X., et al.: Monitoring by remote sensing of vegetation growth in the project of grassland withdrawn from grazing in countries of China. Acta Prataculturae Sinica 16(5), 13-21 (2007) 